\title{
Budaya Literasi dan Jurnalisme Supermarket (Studi Kasus Harian Pagi Jawa Pos, Surabaya)
}

\author{
Culture of Literacy and Supermarket Journalism \\ (Case Study of Jawa Pos Daily, Surabaya)
}
Sitasi: Abror, D. (2020). Budaya Literasi dan Jurnalisme Supermarket
(Studi Kasus Harian Pagi Jawa Pos, Surabaya). PRoMEDIA. Volume 6 (1), Juni 2020, hal 176- hal 213

Dikirim: 4 Mei 2020, Direvisi: 21 Mei 2020, Diterima: 16 Juni 2020, Terbit: 18 Juni 2020

Abstract
Jawa Pos Morning Daily is one of the largest media conglomerate in Indonesia published from East Java, with total circulation 350.000 copies. It is known with distinctive journalism style with colorful pages, large and attractive pictures, advanced page design, and highly variative rubrication. Jawa Pos also known with its simple and communicative language capable of reaching out vast section of readers from lowly market to the high. This journalism formula is self-termed 'Supermarket Journalism' meaning a journalism concept aimed at serving whole section of society. With this formula Jawa Pos circulation grows to become the largest in East Java surpassing all national publications including quality newspaper Kompas. This is achieved amid low literacy culture in Indonesia. A study by UNESCO shows that among 61 countries surveyed Indonesia ranks $60^{\text {th }}$ only a strip above Botswana in the bottom of the list. This paper is to reveal how, by applying Supermarket Journalism formula, Jawa Pos thrives to become the largest newspaper in East Java amid low literacy culture. The same formula is also successfully applied to all Jawa Pos media subsidiaries 
throughout Indonesia so that total Jawa Pos Group circulation overtakes Kompas-Gramedia Group's. This study applies qualitative-descriptive methodology with case study approach. Indepth interviews and focus group discussion are used to gather and enrich data. To understand literacy culture and the media this research uses the theory of Understanding Media of McLuhan. Mass Communication theory of McQuail and media theory of Hallin and Mancini are applied to understand Supermarket Journalism concept. The study shows that Supermarket Journalism succeeds in attracting large section of readers amid low literacy culture of society.

Keywords: Supermarket Journalism, Jawa Pos, Reading Habit, Literacy Culture

\section{Abstraksi}

Harian Pagi Jawa Pos adalah salah satu media konglomerasi terbesar di Indonesia dari Jawa Timur dengan oplah 350.000 eksemplar. Koran ini dikenal dengan gaya jurnalisme yang khas, dengan tampilan penuh warna, foto-foto besar mencolok, grafis desain yang menarik, serta rubrikasi yang sangat bervariasi. Jawa Pos juga mempunyai gaya bahasa yang sederhana dan mudah dipahami yang bisa menjangkau semua kalangan pembaca, dari kelas paling bawah sampai kalangan menengas ke atas. Konsep jurnalisme ini disebut sebagai 'Jurnalisme Supermarket', yaitu jurnalisme yang bisa melayani semua kalangan pembaca. Dengan konsep ini Jawa Pos bisa meraih pembaca tertinggi di Jawa Timur mengalahkan koran-koran nasional termasuk Kompas. Capaian ini didapat di tengah kondisi budaya membaca (literasi) masyarakat Indonesia yang sangat rendah. Studi UNESCO mengenai minat baca menunjukkan bahwa dari 61 negara Indonesia berada di posisi ke-60, hanya setingkat di atas Botswana di posisi jurukunci. Penelitian ini akan mengungkap bagaimana di tengah kondisi budaya baca yang rendah Jawa Pos berhasil menerapkan strategi jurnalisme yang tepat sehingga bisa menjadi koran terbesar di Jawa Timur. Formulasi yang sama juga 
dipakai Jawa Pos untuk mengembangkan koran-koran anak usahanya di seluruh Indonesia, sehingga total oplah Jawa Pos Group mengungguli kelompok Kompas-Gramedia. Studi ini memakai metodologi kualitatif-diskriptif dengan pendekatan studi kasus. Wawancara mendalam (indepth interview) dan FGD (Focus Group Discussion) dipakai untuk pengumpulan dan pengayaan data. Untuk menelusuri budaya baca dan hubungannya dengan media, studi ini menerapkan Teori Understanding Media dari McLuhan dan Teori Mediamorphosis Roger Fiddler. Jurnalisme Supermarket dalam studi ini menerapkan Teori Komunikasi Massa McQuail dan Teori Media Hallin dan Mancini. Hasil studi menunjukkan bahwa formula Jurnalisme Supermarket berhasil menarik pembaca dalam jumlah besar di tengah kondisi rendahnya minat baca masyarakat.

Kata Kunci: Jurnalisme Supermarket, Jawa Pos, Minat Baca, Budaya Literasi

\section{PENDAHULUAN}

Dari sebuah bangunan tua kecil berarsitek kuno di sebuah distrik perdagangan tua di Surabaya bagian utara yang agak kumuh, tepat di seberang Jembatan Merah yang bersejarah, sebuah sejarah pers Indonesia telah lahir. Di Jl Kembang Jepun no 167-169 itulah Harian Pagi Jawa Pos (JP) pada 1982 memulai sejarah baru dengan masuknya Dahlan Iskan sebagai reporter Majalah Mingguan Tempo di Jawa Timur, sebagai pemimpin redaksi baru.

Jawa Pos terlahir sebagai Java Post pada 1 Juli 1949 oleh seorang pedagang Tionghoa bernama The Chung Shen adalah koran kecil yang namanya tidak pernah dikenal di luar lingkaran Surabaya. Di Surabaya pun JP hanya menjadi bayang-bayang 
Surabaya Post, surat kabar sore berkualitas yang dikelola suamiistri R. Abdul Aziz dan Toety Aziz yang merajai pemasaran suratkabar di Surabaya dan Jawa Timur. Meski lahir lebih belakangan pada 1953, tetapi Surabaya Post dengan jurnalisme berkualitas (quality jurnalism) yang khas menjadi penguasa tanpa pesaing berarti sampai munculnya Jawa Pos di bawah Dahlan Iskan.

Dengan oplah awal tidak lebih dari 6.000 eksemplar sertiap hari, dalam rentang waktu sepuluh tahun Jawa Pos secara fenomenal menembus oplah 100.000 eksemplar dan mengambil alih pasar di Surabaya dan Jawa Timur dari Surabaya Post yang rata-rata beroplah 40.000 setiap hari. Bukan hanya menyalip Surabaya Post, Jawa Pos dalam tempo sepuluh tahun kemudian menjadi konglomerasi media cetak terbesar di Indonesia mengalahkan Kompas-Gramedia yang sudah terlebih dahulu mapan (Lim, 2011).

Jawa Pos dengan cepat melakukan penetrasi pasar yang agresif di Surabaya dan Jawa Timur, dan kemudian mengembangkan sayap perusahaan dengan membentuk korankoran di daerah di bawah bendera JPNN (Jawa Pos News Network). Dalam tempo relatif singkat, jaringan JPNN yang menaungi Jawa Pos Group ini menembus seluruh provinsi di Indonesia sampai ke seluruh kota dan kabupaten kecil. Total jumlah media di bawah Jawa Pos Group mencapai 170 surat 
kabar, 21 televisi lokal, dan puluhan percetakan di seluruh Indonesia.

Jawa Pos juga ditahbiskan sebagai suratkabar dengan oplah terbesar di Indonesia dengan total oplah 842 ribu, mengalahkan total oplah Kompas yang mencapai 751 ribu (Data Nielsen Consumer and Media View-CMV-2017).

Sebelum mengalahkan Kompas, Jawa Pos terlebih dahulu menjadi penguasa lokal dengan mengalahkan Surabaya Post yang sudah terlebih dahulu eksis (Surabaya Post resmi tutup pada 2012 setelah berpindah beberapa pemilik). Pada 1982, PT Grafitti Pers yang menerbitkan Majalah Berita Mingguan (MBM) Tempo membeli seluruh saham Jawa Pos dari pemilik lama The Chung Shen (Suseno Tedjo). Saham terbesar PT Grafitti Pers dipegang oleh konglomerat properti, Ciputra, yang menugaskan Eric F.H Samola sebagai direktur utama. Ciputra kemudian menugaskan Samola untuk mengakuisi Jawa Pos untuk mengembangkan sayap perusahaan media ke Indonesia Timur.

Eric Samola menunjuk Dahlan Iskan, yang saat itu adalah kepala biro MBM Tempo di Jawa Timur, sebagai pemimpin redaksi baru Jawa Pos. Duet Eric Samola sebagai direktur utama (CEO) dan Dahlan Iskan sebagai pemimpin redaksi ini sukses dalam mengembangkan Jawa Pos. Samola bertugas menjalankan manajemen sementara Dahlan lebih berkonsentrasi membenahi redaksi. Dalam perjalanannya, Dahlan praktis menjalankan semua fungsi Samola karena Samola banyak menghabiskan waktunya di 
Jakarta. Jadilah Dahlan Iskan sebagai CEO sekaligus pemimpin redaksi. Dua fungsi ini dijalankan dengan baik oleh Dahlan, terbukti dari oplah yang terus-menerus naik dengan tajam.

Tradisi manajemen media modern mengenal adanya Firewall Theory atau Teori Tembok Api yang memisahkan secara rigid antara kepentingan redaksional dengan urusan-urusan bisnis. Dua departemen itu dipisahkan oleh tembok api supaya tidak saling memengaruhi. Redaksi harus independen dan imparsial (tidak memihak) dalam menjalankan kebijakan redaksional (editorial policy), termasuk dari kepentingan bisnis perusahaan media itu sendiri. Pemisahan yang sangat ketat seperti ini diterapkan di media-media besar di Amerika Serikat, seperti The New York Times dan The Washington Post. Saking ketatnya sampai seorang pemimpin redaksi Washington Post melakukan walk out, meninggalkan ruang rapat ketika seorang direksi mencoba mempertanyakan sebuah kebijakan redaksional (Abramson, 2019).

Di Indonesia hal semacam ini juga berlaku pada mediamedia besar seperti Kompas dan MBM Tempo. Tetapi, pada dekade pertengahan 1980-an, ketika media di Indonesia mulai memasuki era industrialisasi, pemisahan redaksi dengan bisnis pelan-pelan mulai memudar seiring dengan semakin ketatnya persaingan memperebutkan kue iklan. Bagian rerdaksi kemudian bersedia melakukan sinergi dengan bagian iklan untuk menghasilkan 'berita iklan'" atau advertorial (advertising dan 
editorial). MBM Tempo kemudian memperkenalkan rubrik 'Pariwara" yang merupakan rubrik advertorial. Kompas punya rubrik "Seremonia" dan mempunyai tim iklan yang dilengkapi dengan keterampilan redaksional untuk menulis advertorial.

Jawa Pos lebih longgar dalam penerapan tembok api, karena praktis Dahlan Iskan yang mengendalikan departemen redaksi dan bisnis di tengah absennya Eric Samola (Samola meninggal dunia 2001). Hal inilah yang, antara lain, membuat Jawa Pos lebih lentur dan lincah dalam mengambil keputusan, karena Dahlan Iskan praktis mengendalikan semua keputusan-keputusan strategis-praktis.

Karena Dahlan adalah wartawan MBM Tempo maka gaya redaksional Tempo memengaruhi Jawa Pos, meskipun sebagian. Dalam khazanah jurnalisme Indonesia gaya penulisan Tempo dikenal sebagai genre 'Jurnalisme Sastrawi'. Ada juga yang menyebutnya sebagai "Jurnalisme Literer', atau yang lebih sederhana disebut sebagai "Jurnalisme Bertutur" atau 'Jurnalisme Deskriptif' (Steele, 2004).

Penulisan literer ala Tempo membutuhkan keterampilan menulis yang spesial. Dalam istilah Steele (2004), wartawan Tempo tidak sekadar jurnalis tetapi mereka adalah penulis (writer) dengan keterampilan literer (sastrawi) yang mumpuni. Goenawan Mohamad, pemimpin redaksi Tempo, adalah seniman, budayawan, sastrawan, cum wartawan. Beberapa awak redaksi Tempo seperti Syu'bah Asa juga adalah budayawan cum 
wartawan. Tak heran Tempo bisa menghasilkan jurnalisme sastrawi kelas tinggi yang "Enak Dibaca dan Perlu" sebagaimana mottonya.

Dengan segala keterbatasan kemampuan redaksi di Jawa Pos, Dahlan mengambil unsur-unsur jurnalisme Tempo. Ia kemudian mengadopsi jurnalisme bertutur dan deskriptif ala Tempo dan menerapkannya di Jawa Pos. Dahlan menyebut Jawa Pos sebagai 'Tempo yang Terbit Setiap Hari'. Ia memakai bahasa bertutur yang mengalir sederhana dan memadukannya dengan idiom-idiom khas Jawa Timur. Kalau Tempo membidik pangsa pasar kelas atas premium dengan jurnalisme sastrawi, Jawa Pos ingin membidik semua kalangan dari menengah ke atas sampai kelas paling bawah. Dahlan Iskan kemudian menyebut genre ini sebagai 'Jurnalisme Supermarket' (Wawancara, 2018). Strategi ini dimaksudkan sebagai upaya penetrasi untuk menembus pasar Jawa Timur yang masih didominasi oleh budaya literasi yang rendah. Sebuah studi literasi budaya yang diselenggarakan oleh UNESCO menunjukkan bahwa dari 61 negara yang disurvei Indonesia berada di ranking ke-60, hanya satu strip di atas Botswana di posisi jurukunci. Data Departemen Pendidikan dan Kebudayaan RI menunjukkan bahwa ranking minat baca Jawa Timur ada di urutan 26. Sementara itu, data Kominfo 2018 menunjukkan masyarakat Indonesia membaca 27 halaman buku pertahun dan membaca surat kabar 12 sampai 15 menit perhari (Data Kominfo, 2018). 
Di tengah kondisi ini, Jawa Pos menerapkan formula 'Jurnalisme Supermarket' untuk menembus pasar Jawa Timur. Jawa Pos menerapkan gaya bahasa yang sederhana dan mudah dipahami kalangan menengah ke bawah. Jawa Pos juga memilih angle (sudut) berita yang ringan, unik, dan terkadang cenderung remeh, misalnya model baju yang dikenakan seorang menteri, tingkah lucu seorang pejabat, atau makanan yang dipilih seorang selebritas. Pemilihan angle semacam ini lazm disebut sebagai soft news (Ishwara, 2005), dan di lingkungan redaksi Jawa Pos disebut sebagai color news (warna-warni berita).

Pada dasarnya yang dilakukan Jawa Pos adalah menerapkan jurnalisme bertutur dan deskriptif ala Tempo dengan modifikasi ala Jawa Pos. Dahlan Iskan menyebut gaya bahasa Jawa Pos pada masa-masa awal sampai sekarang sebagai 'Tempo yang terbit setiap hari'" (wawancara, 2018), tanpa merujuk pada Koran Tempo yang baru terbit pada 2005.

Selain Tempo dengan gaya Jurnalisme Sastrawi dan Jawa Pos dengan gaya Jurnalisme Supermarket, Harian Kompas mempunyai gaya jurnalistik khas yang disebut sebagai 'Jurnalisme Makna"' yang diperkenalkan oleh pendiri Kompas, Jacob Oetama. Menurut dia, seorang wartawan seyogianya tidak hanya memberitakan sebuah peristiwa, tapi masuk lebih jauh menggali apa makna dari peristiwa itu. Seorang wartawan harus mampu mengambil jarak atas peristiwa yang ditulisnya dan menarik sebuah refleksi atas peristiwa tersebut. Dengan begitu, 
pembaca mendapatkan enlightment atau pencerahan. Tugas media adalah mencari dan menghadirkan makna dari peristiwa dan masalah, besar dan kecil (Oetama, 2003).

Gaya Jurnalisme Supermarket yang dipakai Jawa Pos berhasil menembus pasar Jawa Timur. Terbukti, dalam 10 tahun sejak dikelola Dahlan Iskan oplah Jawa Pos menembus 100 ribu pada awal 1992 dan berhasil menyalip Surabaya Post. Tetapi, risikonya adalah Jawa Pos dianggap sebagai koran populer (popular paper) yang merupakan antitesis dari koran berkualitas (quality paper). Gaya jurnalisme Jawa Pos disebut melakukan "reaching out"' (menjangkau pasar), tetapi di sisi lain juga melakukan "dumbing down" atau pendangkalan (McNair, 2004) Abdul Rokhim, pemimpin redaksi Jawa Pos saat ini, tidak sepakat dengan terminologi "reaching out, dumbing down" dari McNair. Jurnalisme Jawa Pos memang mengikuti tren pasar pembaca, tetapi tidak sepenuhnya menyerah kepada selera pasar. Edukasi literer tetap dilakukan oleh Jawa Pos dengan pemilihan sudut berita yang berkualitas dan menyajikannya dengan bahasa yang sederhana (wawancara, 2019).

\section{TINJAUAN PUSTAKA}

\section{A. Budaya Literasi}

Roger Fidler (1987) menyebut peradaban manusia dalam tiga tahapan. Budaya Tutur (Spoken Language), Budaya Tulis (Written Language), dan Budaya Digital (Digital Language). 
Ketiga tahapan itu adalah metamorfosa media yang disebutnya sebagai "Mediamorfosis". Budaya tutur terjadi sejak masa prasejarah sampai dengan abad pertengahan dimana manusia melakukan komunikasi dengan tutur kata dan simbol-simbol bahasa. Ketika manusia sudah menemukan bahasa yang berkembang dan dipahami oleh masyarakat yang lebih luas mereka memakai story telling (menceritakan peristiwa) untuk mengemukakan gagasan-gagasannya. Ketika itu ilmu pengetahuan belum berkembang luas karena hanya dipahami oleh sedikit kalangan elite. Kekuasaan raja-raja feodal juga sangat kuat karena rakyat tidak banyak memahami ide-ide kebebasan. Gereja sebagai otoritas keagamaan juga mempunyai pengaruh yang kuat karena pengetahuan mengenai agama hanya dimonopoli oleh kalangan pendeta saja (Ferguson, 2015).

Pada abad ke-15 Gutenberg menemukan mesin cetak di Jerman. Sejak itu revolusi literasi menyebar dengan sangat cepat di Eropa. Penemuan mesik cetak seperti membuka cakrawala baru dan dunia membentang luas sebagaimana galaksi yang terbuka lebar. Era baru ini disebut sebagai 'Gutenberg Galaxy', (Castells, 2004). Dalam waktu singkat buku-buku dicetak dan disebar ke segala penjuru Eropa. Kitab Suci Injil yang sebelumnya hanya dimonopoli kalangan elite agama kemudian dicetak secara luas dan dibaca oleh kalangan awam. Otoritas gereja mulai berkurang karena masyarakat umum bisa membaca Kitab Suci secara langsung. 
Selamat datang di era literasi baca. Mesin cetak Gutenberg melahirkan revolusi ilmu pengetahuan dengan lahirnya pemikirpemikir positivistik seperti August Comte dan juga Emannuel Kant yang memperkenalkan rasionalitas dengan semboyan "Sapere Aude" atau Gunakan Akalmu. Maka kemudian lahirlah revolusi berpikir melalui gerakan pencerahan akal budi yang disebut sebagai Aufklarung atau Enlightment di abad ke-18 (Sindhunata, 2019).

Inilah era ketika komunikasi massa mulai tumbuh menjamur dengan terbitnya surat kabar pertama di Inggris dan Amerika yang menyebarkan ide-ide pembaruan dan demokrasi. Surat kabar, pers, menjadi bagian sangat penting dari peradaban modern abad ke-19 bersamaan dengan munculnya gerakan demokrasi menyusul Revolusi Prancis 1789. Negara-negara demokrasi modern Eropa lahir dengan menerapkan teori Trias Politika tiga pilar Montesqieu; eksekutif, legislatif, judikatif. Pers kemudian mengambil peran penting sebagai Pilar Keempat Demokrasi, The Fourth Pillar of Democracy yang melengkapi mekanisme checks and balances dalam pelaksanaan demokrasi (McNair, 2004).

Revolusi teknologi berkembang cepat melahirkan berbagai inovasi ilmu pengetahuan. Setelah James Watt menemukan kapal uap sebagai awal revolusi industri lahirlah berbagai jenis teknologi sampai ditemukannya gelombang elektromagnetik yang menghasilkan radio transistor yang menjadi wahana baru manusia 
berkomunikasi melalui media. Inilah perubahan metamorfosis yang dialami oleh media dari era cetak menuju era audio yang oleh Fiddler (1987) disebut sebagai 'Mediamorfosis".

Radio menjadi penemuan baru yang cepat berkembang sebagai sarana komunikasi massa baru dengan gaya jurnalisme yang berbeda dengan cetak. Keduanya sama-sama berkembang dan tidak saling mematikan. Demikian pula ketika ditemukan televisi yang memadukan gambar visual dengan suara audio pada awal 1960-an. Dengan cepat televisi berkembang menjangkau mayoritas rumah tangga Amerika Serikat dan mengubah pola konsumsi media mereka. Kendati demikian, televisi tidak mematikan perkembangan radio maupun suratkabar. Ketiga jenis komunikasi massa itu malah saling mengisi dan melengkapi dan melakukan konvergensi (Ishadi, 2004).

Fidler (1987) mengelompokkan suratkabar, radio, dan televisi dalam kategori era yang sama yaitu "written era". Meskipun suratkabar berbasis cetak dan radio-televisi berbasis broadcast tetapi ketiganya dikelompokkan sebagai media analog yang disebut sebagai media mainstream (media arus utama) untuk membedakannya dengan media baru (new media) yang berbasis digital (Nashrullah, 2014).

Era digital ditandai dengan munculnya komunikasi massa berbasis komputer dan internet yang oleh Livingstone (2015) disebut sebagai CMC (computer mediated communication), komunikasi dengan mempergunakan komputer dan internet 
sebagai medianya. Fidler (1987) mengategorikannya sebagai "digital era" dengan menjamurnya media baru berbasis digital. Inilah era globalisasi yang menyatukan seluruh planet bumi menjadi satu kesatuan karena terhubungkan oleh jaringan World Wide Web (www) melalui jaringan internet. Dunia global ini seolah menyusut menjadi desa kecil yang oleh McLuhan disebut sebagai Desa Buana atau Global Village (McLuhan, 1964).

Pola komunikasi berubah drastis oleh kemunculan teknologi digital yang diikuti oleh menggelontornya gelombang informasi menjadi tsunami informasi. Ekosistem media massa berubah dengan munculnya media digital yang sangat mengandalkan kecepatan. Kemunculan media sosial mengubah pola hubungan sosial dan konsumsi media, masyarakat dunia terkoneksi menjadi satu dalam sebuah Network Society (Castells, 2010).

Berbeda dengan kemunculan radio dan televisi yang bisa berkonvergensi dengan suratkabar, kemunculan new media berbasis digital ini diprediksikan akan mengancam eksistensi suratkabar, radio, dan televisi (Sudibyo, 2019). Penetrasi internet berlangsung sangat cepat, dan saat ini diperkirakan 60 persen penduduk bumi yang berjumlah 7 miliar sudah tersambung oleh internet. Dari sekitar 4 miliar pengguna internet di seluruh dunia sekitar 2,3 miliar adalah pengguna Facebook sebagai sarana bermedia sosial. Kemunculan Facebook sebagai media sosial, Google sebagai mesin pencari (search engine) sekaligus mesin pengumpul berita (news aggregator) dan Amazon sebagai sarana 
perdagangan elektronik (e-commerce) mengancam eksistensi suratkabar, radio, dan televisi sebagai media arus utama. Budaya baca masyarakat berubah total karena kemunculan internet dan media sosial, jika sebelumnya suratkabar menjadi sumber berita, radio menjadi sumber infomasi sosial, dan televisi sebagai sumber hiburan, maka semuanya terancam oleh internet yang bisa menyediakan semua kebutuhan itu secara cerpat dan gratis (Sugihartati, 2014).

Marshall McLuhan (1964) membagi fase peradaban manusia dalam empat tahapan; Era Tribal, Era Terpelajar, Era Tertulis, dan Era Elektronik. Era Tribal, adalah era tradisi lisan yang mengandalkan pembicaraan dan pendengaran sebagai indra yang sangat penting. Di era ini telinga merupakan pusat dari budaya masyarakat. Dengan mendengar dan berbicara manusia saling berkomunikasi dan membentuk masyarakat kolektif.

Era Terpelajar adalah era komunikasi tertulis dimana mata menjadi indra yang dominan, dan era ini ditandai dengan ditemukannya abjad dan huruf. Di era ini komunikasi tatap muka tidak lagi dilakukan secara lansung karena sudah ditemukan tulisan. Komunikasi tatap muka langsung sudah mulai berkurang karena manusia berkomunikasi melalui tulisan. Masyarakat yang semula komunal berangsur-angsur menjadi individualistis.

Era Tertulis, adalah era dimana masyarakat mendapatkan informasi-informasi melalui kata-kata tercetak dan penglihatan menjadi indra yang dominan. Era ini ditandai dengan kelahiran 
media cetak oleh Gutenberg di abad ke-15. Media cetak kemudian menjadi ini salah satu sarana dalam memenuhi kebutuhan informasi.

Era Elektronik, adalah era dimana media elektronik melingkupi semua indera kita, dan memungkinkan orang-orang di seluruh dunia untuk terhubung. Era ini merupakan masa radio dan televisi serta munculnya media baru karena perkembangan teknologi informasi seperti media sosial.

\section{B. Budaya Literasi di Indonesia}

Sugihartati (2014) menyebut terjadi anomali dalam budaya literasi di Indonesia. Dalam perspektif periodesisasi McLuhan dan Fidler, sebuah era awal merupakan pondasi bagi era berikutnya. Era spoken language merupakan pondasi bagi munculnya era written language, dan kemudian era written language manjadi dasar bagi perkembangan era digital language. Dalam perspektif McLuhan "era tertulis" menjadi dasar bagi "era terpelajar" yang kemudian berkembang menjadi 'era elektronik". Satu era ke era lainnya merupakan tahapan yang saling berhubungan.

Di Indonesia terjadi beberapa lompatan era. Secara kultural masyarakat Indonesia adalah masyarakat kolektif yang suka berkomunikasi dengan berbicara langsung satu sama lain. Ketika muncul era "written" atau "'era tertulis" dan 'era terpelajar', budaya komunalisme masyarakat masih tetap utuh tidak banyak 
berubah. Budaya komunalisme yang kental ini membuat masyarakat enggan mengembangkan budaya tulis, dan hal ini mengakibatkan rendahnya minat baca dan tulis (Mulyana, 2019).

Ketika budaya baca-tulis belum kuat di Indonesia kemudian muncul era elektronik dan digital yang serbuannya lebih dahsyat. Masyarakat Indonesia mengalami gegar budaya (culture shock) dan gegar peradaban (civilization shock) yang hebat akibat perkembangan elektronik dan teknologi informasi. Masyarakat yang belum gemar membaca akan semakin malas membaca karena kemunculan televisi. Terjadilah gegar budaya disini. Dan, ketika sekarang muncul media digital dan media sosial masyarakat Indonesia mengalami gegar peradaban karena pondasi peradaban baca-tulisnya masih lemah (Nasrullah, 2015).

Data UNESCO dan Data Kominfo menunjukkan anomali itu. Minat baca masyarakat Indonesia sangat rendah, urutan ke-60 dari 61 negara. Sementara dalam penggunaan internet dan media sosial Indonesia berada di tiga besar dunia di bawah China dan Amerika Serikat. Literasi media yang rendah menyebabkan bangsa Indonesia rentan terhadap serangan berita palsu (fake news) dan berita bohong (hoax) (Sudibyo, 2019).

\section{Jurnalisme Supermarket}

Media-media besar mempunyai genre jurnalistiknya masingmasing. Kompas memperkenalkan Jurnalisme Makna yang menekankan pentingnya melihat berita dengan perspektif yang 
lebih dalam. Sebagaimana ditulis dalam buku 'Syukur Tiada Akhir; Jejak Langkah Jakob Oetama" (2011) Oetama mencermati nilai-nilai yang ditanamkan dan disebarkan melalui berita di Kompas, terutama soal kemanusiaan, pendidikan, kebudayaan, dan kecintaan terhadap negara Indonesia.

Kompas menerapkan jurnalisme makna sebagai implementasi budaya Jawa yang melakukan kritik tanpa harus berbicara tegas dan langsung. Kompas menampilkan berita tanpa prasangka buruk dengan sikap hati yang santun. Jakob menempatkan lembaga media sebagai lembaga pendidikan bagi masyarakat, dan ia konsisten membangun masyarakat melalui jurnalisme pembangunan, jurnalisme fakta, dan jurnalisme makna. Suatu prinsip yang menuntut wartawan terus belajar dalam memperkaya dan memberi penafsiran atas suatu berita, tanpa mengubah fakta yang diperoleh di lapangan, sehingga pembaca bisa cerdas dan tercerahkan. (Sularto, 2011)

Pada 17 April 2003, Jakob menerima gelar Doktor Honoris Causa dari Universitas Gadjah Mada, Yogyakarta. Seperti yang ditulis Sularto (2011), dalam pertimbangan Senat Akademik UGM, Jakob sejak 1965 dinilai berhasil mengembangkan wawasan dan budaya jurnalisme bernuansa sejuk yang menjadi referensi di Indonesia. Sikap boleh keras tapi penyampaian tetap lentur dan santun. Di bawah Jakob terjadi metamorfosis pers, dari pers yang sektarian menjadi media massa yang merefleksikan inclusive democracy dengan meletakkan nilai manusia dan 
kemanusiaan pada posisi sentral pemberitaan. Sama halnya dalam menghadapi hidup yang kompleks, Jakob berfokus pada bagaimana kemanusiaan menjadi basis kegiatan, dan bagaimana latar belakang mengaruhi pengembangan masyarakat manusia semakin manusiawi.

Gaya jurnalisme Jawa ala Jakob ini dikritik oleh jurnalis senior Rosihan Anwar yang menyebut jurnalisme Kompas sebagai "Jurnalisme Kepiting", yaitu berjalan merambat ketika situasi aman dan berhenti ketika situasi rawan. Hal ini diakui sendiri oleh Oetama dalam bukunya 'Pers Indonesia; Berkomunikasi dalam Masyarakat Tidak Tulus"' (2001).

Majalah Tempo yang terbit pada 1971 membawa genre baru di dunia media di Indonesia. Didirikan sekelompok wartawan muda yang berlatar belakang seniman dan budayawan, seperti Goenawan Mohamad, Tempo memperkenalkan jurnalisme sastrawi yang merupakan paduan jurnalisme dengan penulisan sastra (Steele, 2005).

Prinsip jurnalisme sastrawi adalah laporan jurnalisme dengan menerapkan gaya penulisan sastra dengan menampilkan elemenelemen seperti karakter, alur, detail, penyusunan adegan, struktur, drama, konflik, dialog, dan metafora. Jurnalisme sastra dipelopori oleh Truman Capote yang menulis karya monumental 'In the Cold Blood"' (1966) yang menjadi novel non-fiksi laris pada saat itu. Buku ini merupakan hasil liputan investigatif yang ditulis 
secara literer dan betul-betul didasari oleh fakta yang diverifikasi dengan sangat teliti.

Pada 1973, Tom Wolfe memperkenalkan penulisan laporan jurnalistik ini dengan menyebutnya sebagai New Journalism yang kemudian disebut juga sebagai literary journalism dan di Indonesia dikenal sebagai jurnalisme sastrawi yang dipelopori Tempo. Prof Janet E.Steele ahli sejarah dari George Washington University, Amerika Serikat melakukan penelitian di Indonesia selama tiga tahun untuk melihat gaya jurnalisme Tempo. Penelitian ini kemudian ditulis dengan gaya jurnalisme sastrawi dalam buku monumental 'The Wars Within: The Story of Tempo an Independent Magazine in Soeharto's Indonesia' ' (2005).

Jurnalisme Jawa Pos oleh Dahlan Iskan diarahkan untuk mengadopsi jurnalisme Tempo. Tetapi, dengan keterbatasan sumber daya redaksi Jawa Pos sangat sulit untuk melakukannya. Dahlan kemudian mengambil unsur-unsur jurnalisme sastrawi dan menerapkannya dalam jurnalisme Jawa Pos. Beberapa unsur paling penting yang diadopsi adalah penulisan features berdasarkan kisah-kisah daya tarik manusia (human interest), penulisan dengan gaya deskripsi yang detail, dan penulisan berdasarkan observasi yang ringan tapi menarik mengenai tingkah laku yang unik seorang pejabat, cara berbicara seorang publik figur, atau gaya berpakaian seorang seorang selebritas, yang oleh Jawa Pos disebut sebagai color news (Wawancara, 2017). 
Selain sumber daya redaksi yang tidak sebanding dengan Tempo, target pembaca Jawa Pos juga berbeda dengan Tempo. Tempo membidik pasar terpelajar kelas atas dalam kategori ekonomi A, sedangkan Jawa Pos membidik seluruh segmen dari kelas C sampai dengan B plus maupun A. Maka Jawa Pos menerapkan gaya bahasa yang lebih popular dan sederhana. Menurut ahli jurnalis senior dan ahli bahasa Dr. Hernani Sirikit, gaya bahasa Jawa Pos yang popular dan tidak tinggi seperti Surabaya Post maupun Kompas sangat ideal untuk meraih pembaca yang range-nya lebih heterogen. Mereka yang lulus SD maupun kalangan eksekutif, akademisi, dan birokrat tinggi samasama merasa nyaman membaca Jawa Pos. Dahlan Iskan dengan semena-mena menyebut genre ini sebagai 'Jurnalisme Supermarket" yang bertujuan untuk menyediakan semua kebutuhan konsumen dengan latar belakang beraneka (Wawancara, 2019).

\section{Kerangka Teori}

Dalam melihat industri pers Hallin dan Mancini (2002) mempergunakan empat variabel. Pertama, Industri Pers; yaitu kuat atau lemahnya sirkulasi media. Kedua, Paralelisme Politik, yaitu hubungan media dengan kekuatan-kekuatan politik yang ada di masyarakat; sistem media merefleksikan kekuatan politik. Ketiga, Profesionalisme Jurnalis. Keempat, Intervensi Pemerintah terhadap Pers. 
Secara umum empat variabel yang dipakai Hallin dan Mancini sesuai dengan kondisi di Indonesia. Pers Indonesia tidak pernah bisa lepas dari faktor paralelisme politik. Pada era Soeharto, pers dikontrol dengan sangat ketat sehingga fungsi kontrol hampir mandul. Pers kemudian menerapkan kebijakan redaksional untuk menghindari tindak kekerasan penguasa berupa pembreidelan. Karena itu, Kompas memilih jalan aman dengan menerapkan Jurnalisme Makna. Tempo membungkus jurnalismenya dengan Jurnalisme Sastrawi. Ketika melakukan kritik Kompas melakukannya dengan 'penuh makna'. Ketika Tempo melakukan kritik terhadap kekuasaan hal itu dilakukannya secara 'sastrawi', Jawa Pos yang sejak awal memilih kebijakan redaksional yang apolitis lebih asyik dengan membuka "supermarket jurnalisme", untuk meraup pelanggan sebanyak mungkin.

Meskipun penekanan Hallin dan Mancini dengan empat variabel itu adalah perbandingan sistem pers di beberapa negara, tetapi pendekatan yang digunakannya memadai utuk dipakai melihat sistem pers di sebuah wilayah di suatu negara, termasuk Indonesia. Bahkan, untuk membandingkan sistem pers di banyak negara, pendekatan Hallin dan Mancini cukup memadai untuk melihat pers di wilayah-wilayah yang berbeda. Memang ada kritik bahwa pendekatan mereka terlalu mempertimbangkan faktor politik, namun, sebagaimana dalam banyak kasus, kaitan keduanya memang sangat erat, seperti yang terjadi di Indonesia. 
Jawa Pos, sebagaimana Kompas, Tempo, dan banyak media mainstream di Indonesia adalah media produk Orde Baru, lahir dan tumbuh kembang di zaman otoritarianisme Orde Baru. Karena itu media-media itu apolitis, menghindari sikap politik yang konfrontasional dan memilih jalan tengah yang aman. Dalam telaah ekonomi-politik media, Mosco (2001) melihat institusi media sering memberi perhatian yang jauh lebih besar pada kepentingan bisnis dibanding kepentingan idealisme. Pada era 1980 dan 1990-an pers Indonesia sedang asyik mengembangkan konglomerasi bisnis untuk menghindari benturan dengan Orde Baru. Pengembangan konglomerasi dilakukan secara vertikal (hilir ke hulu), secara horisontal dengan mengembangkan anak perusahaan baru, dan juga mengembangkan bisnis yang sama sekali diluar media (Golding dan Murdock, 2007).

Setelah muncul orde Reformasi, pers Indonesia semakin bersemangat mengembangkan konglomerasi setelah pemerintah menerapkan deregulasi dan liberalisasi industri media. Puluhan media baru lahir dari Jawa Pos Group, hampir di semua ibukota kabupaten-kota di seluruh Indonesia Jawa Pos mempunyai media di bawah payung Radar. Sedangkan Kompas mengembangkan konglomerasi melalui kelompok Tribun. Karakter konglomerasi, sebagaimana diungkap oleh McChesney (2001), kurang memedulikan kualitas redaksional dan lebih tertarik untuk mengembangkan sisi komersial media. 
Dennis McQuail (2011) mengajukan teori normatif empat model, yaitu Model Pluralis Liberal atau Pasar, Model Tanggung Jawab Sosial atau Kepentingan Publik, Model Profesional, dan Model Media Alternatif.

Dalam model pluralis-liberal, media beroperasi di atmosfer persaingan bebas tanpa campur tangan pemerintah sama sekali. Dalam model tanggung jawab sosial, pers bebas bersaing tetapi tetap mempunyai tanggung jawab sosial terhadap publik. Media yang bertanggung jawab akan mengembangkan standar yang tinggi, tetapi regulasi pemerintah masih tetap dibutuhkan. Dalam Model Profesional pers yang bebas benar-benar mengabdi kepada kepentingan publik demi menjaga nilai-nilai demokrasi. Pers menjadi ruang publik (public sphere) yang memberi kebebasan publik untuk mengajukan dan memperdebatkan gagasangagasannya. Model Media Alternatif memberi ruang kepada media non-mainstream untuk memainkan peran sosial dan politiknya. Media-media kecil memainkan posisi kritis dan oposisional terhadap kekuatan media mainstream dan kekuatan negara.

Dalam praktik di Indonesia pers lebih dekat pada model pluralis-liberal dengan persaingan bebas tanpa batas. Campur tangan dan regulasi pemerintah terhadap industri pers nyaris tidak ada. Pers akhirnya mengabdi kepada kepentingan pemilik modal dan pemasang iklan. Dalam kondisi demikian pers lebih fokus 
pada pencarian keuntungan dan melupakan fungsinya sebagai penjaga demokrasi (Herman dan Chomsky, 2001).

McNair dalam buku 'Journalism and Democracy; An Evaluation of the Political Public Sphere" (2000) mengajukan teori 'Reaching Out and Dumbing Down'” yaitu meraih pembaca sebanyak mungkin dengan melakukan pembodohan. Dalam hal ini masyarakat digelontor oleh tsunami informasi yang bergelombang, tetapi pada saat yang sama masyarakat tidak mendapatkan 'informasi yang tepat" untuk menjalankan fungsinya sebagai warga negara. Tugas media adalah memenuhi hak publik untuk tahu (fulfilling public's right to know) agar bisa berdaulat dalam menjalankan hak politiknya (Abramson, 2019). Dalam 'Dumbing Down' media tidak cukup menyuplai publik dengan informasi yang baik untuk menjalankan hak demokrasi.

Media kemudian terperangkap pada penyajian berita-berita berselera rendah yang membuat publik gagal mendapatkan pendidikan politik. Berita-berita yang disajikan cenderung sensasional dan lebih banyak menyajikan realitas psikologis dibanding realitas sosiologis (Westersthal, dalam Eriyanto, 2001).

\section{METODOLOGI PENELITIAN}

Studi ini memakai metode kualitatif-diskriptif dalam tradisi penelitian sosial untuk mendapatkan gambaran yang lebih utuh mengenai kebijakan redaksional Jawa Pos (Mulyana, 2010, Sugiono, 2001, Moleong, 2007, Denzin dan Lincoln, 2007). 
Topik ini sangat luas dan banyak dimensi rumit sehingga membutuhkan pendalaman dalam pengumpulan data melalui wawancara mendalam (depth interview) dengan pengambil keputusan di Jawa Pos, yaitu pemimpin redaksi dan direktur utama. Wawancara mendalam dengan founder Jawa Pos Group, Dahlan Iskan, sangat memperkaya dimensi penelitian ini.

Pendekatan studi kasus (Yin, 2007 dan Alwasilah, 2008, Creswell, 2007), dilakukan dengan memperbandingkan secara langsung dengan beberapa media terkemuka, seperti Surabaya Post, Kompas, dan Tempo. Pengalaman peneliti selama 25 tahun di industri media massa membuat peneliti mempunyai akses yang luas terhadap berbagai kalangan media di Surabaya dan seluruh Indonesia. Dalam penelitian ini peneliti bisa mendapat akses yang luas terhadap beberapa media tersebut. Peneliti bisa mewawancarai awak redaksi, redaktur, dan pemimpin redaksi media itu secara sangat terbuka. Peneliti juga mengikuti berbagai rapat penting maupun rutin yang diselenggarakan oleh mediamedia itu. Peneliti juga bisa melalukan observasi langsung di kantor redaksi (newsroom) untuk melihat bagaimana pengambilan keputusan dilakukan.

\section{PEMBAHASAN}

Jawa Pos telah menjadi fenomena dalam sejarah media di Indonesia. Sebagai harian yang terbit dari daerah, Jawa Pos bisa bersaing dengan media terbitan ibukota. Dalam perkembangan terbaru Jawa Pos Group malah bisa mengalahkan Kelompok 
Kompas-Gramedia. Sejak diambil alih oleh PT Grafitti Pers (penerbit Majalah Tempo) pada 1982, Jawa Pos menunjukkan pertumbuhan yang fenomenal. Dari oplah harian rata-rata hanya 6 ribu eksemplar, dalam tempo 10 tahun Jawa Pos bisa menembus oplah 100 ribu eksemplar. Dalam sepuluh tahun berikutnya Jawa Pos bisa menembus oplah dua kali lipat dan bahkan menyentuh angka 350 ribu. Ini adalah capaian yang fenomenal dan sangat sulit dicapai oleh harian manapun di Indonesia.

Dalam kurun waktu 20 tahun itu Jawa Pos berkembang menjadi konglomerasi media dengan jumlah anak perusahaan di seluruh Indonesia mencapai 170 suratkabar dan 21 televisi lokal ditambah dengan sekitar 70 percetakan di seluruh Indonesia. Tak pelak, Jawa Pos adalah perusahaan konglomerasi media yang kaya-raya.

Strategi bisnis yang tepat ditambah dengan kebijakan redaksional yang bagus membuat Jawa Pos bisa diterima oleh masyarakat Jawa Timur dan masyarakat pembaca suratkabar di seluruh Indonesia. Pilihan Jawa Pos untuk menerapkan strategi Jurnalisme Supermarket membuahkan hasil yang bagus. Keberhasilan ini menjadi lebih fenomenal karena dicapai di tengah kondisi budaya literasi masyarakat yang rendah. Jurnalisme Supermarket dilakukan dengan pemilihan bahasa yang sederhana, komunikatif, serta mudah dipahami. Pemilihan engle (sudut) berita dilakukan secara sederhana dengan banyak menyajikan berita features mengenai daya tarik manusia, dan 
berita ringan (soft news) dengan mengambil sisi ringan sebuah peristiwa.

Dengan strategi ini Jawa Pos berhasil melakukan reaching out (meraih pembaca sebanyak mungkin) dari kalangan yang paling bawah sampai ke kalangan tertinggi. McNair (2000) melihat strategi reaching out ini diterapkan oleh media-media cetak Inggris untuk mendapatkan pembaca sebanyak-banyaknya. Strategi redaksional yang diterapkan, secara sinis, oleh McNair disebut sebagai dumbing down atau pembodohan. Media-media Inggris menampilkan apa yang disebut sebagai "tabloidisme" dengan menampilkan berita-berita yang cenderung sensasional yang menyangkut skandal seks, kekerasan, dan kriminal.

Media Inggris menjadikan berita politik bukan sebagai sarana untuk melakukan pendidikan politik, tetapi untuk mendapatkan penjualan koran yang tinggi. Karena itu, Ganz (2004) menyebut media Inggris terobsesi untuk memberitakan skandal seks dalam politik. Kasus perselingkuhan Presiden Clinton dengan Monica Lewinsky di Gedung Putih pada 1999 mendapatkan liputan yang sangat luas oleh media Inggris. Bukan sisi debat politik yang mendapat perhatian media Inggris tetapi sisi-sisi skandal seks-lah yang mendapar liputan mendalam.

Dalam skala tertentu hal yang sama juga terjadi pada Jawa Pos. Meskipun tidak memberitakannya secara vulgar, tetapi Jawa Pos melakukan liputan yang luas dan ekstensif terhadap kasus dugaan skandal perselingkuhan antara Presiden Abdurrahman 
Wahid dengan Aryanti Sitepu pada 2001. Skandal ini, ditambah dengan berbagai skandal ekonomi--seperti Bulog-Gate yang diduga melibatkan orang dekat Presiden Gus Dur-akhirnya membuat Gus Dur jatuh oleh impeachment (pemakzulan) DPR.

Tak disangkal, Jawa Pos menangguk keuntungan ekonomi dari pemberitaan-pemberitaan sejenis ini. Pada tahun-tahun itu ketika gerakan reformasi membawa angin perubahan pada peta politik Indonesia kehidupan pers pun mendapatkan limpahan berkah. Pemerintah Presiden Habibie pada 1998 melakukan deregulasi dan liberalisasi terhadap industri media di Indonesia dengan mencabut kewajiban mempunyai SIUPP (Surat Izin Usaha Penerbitan Pers) bagi media yang hendak terbit. Akibatnya, ribuan media baru lahir seperti jamur di musim hujan tanpa bisa dikontrol. Tanpa keahlian dan profesionalisme yang mencukupi media-media itu tak bisa bertahan lama. Hanya dalam dua tahun media-media itu satu-persatu berguguran. Akhirnya hanya media-media lama yang sudah berpengalaman di masa Orde Baru yang bisa bertahan dan terus berkembang memanfaatkan suasana liberalisasi dan deregulasi.

Pada masa-masa awal reformasi Jawa Pos Group melahirkan puluhan media baru di seluruh Indonesia. Jawa Pos melakukan konglomerasi secara vertikal dan horizontal (Golding dan Murdock, 2000). Secara vertikal Jawa Pos membangun pabrik kertas dan percetakan, dan secara horisontal Jawa Pos melahirkan media-media baru di seluruh Indonesia. 
Dalam waktu relatif singkat, Jawa Pos bisa mengembangkan konglomerasi secara agresif, tetapi efektif dan efisien. Melalui jaringan JPNN (Jawa Pos News Network) Jawa Pos menyebar dan membagikan berita-beritanya ke seluruh anak perusahaan di seluruh Indonesia. Karena itu, pola "Jurnalisme Supermarket', juga menular kepada seluruh anak perusahaaan, dan terbukti anak-anak perusahaan Jawa Pos itu juga menjadi market leader di daerah masing-masing.

Ketika media menjadi kaya kualitas jurnalisme menjadi menurun dan demokrasi menjadi miskin. McChesney (2001) menyebut hal ini dalam bukunya 'Rich Media, Poor Democracy"' (Media Kaya, Demokrasi Miskin). Menurut McChesney, karena sudah menjadi konglomerat yang kaya-raya maka media memberikan perhatian yang lebih pada masalahmasalah finansial dan bisnis sehingga mengabaikan kualitas jurnalisme. Menurut McChesney, konglomerasi media berkorelasi negatif dengan kualitas jurnalisme, semakin kaya media semakin turun kualitas jurnalisme. Media kaya cenderung tidak mau mengelurakan biaya untuk jurnalisme investigasi yang memang membutuhkan biaya tinggi dan waktu yang panjang. Jurnalisme investigasi dianggap sebagai puncak kualitas liputan media (Santana, 2004), karena dengan investigasi itu media bisa membongkar penyelewengan-penyelewengan yang dilakukan oleh kekuasaan, sehingga media bisa lebih efektif dalam 
menjalankan fungsi kontrol sosial sekaligus sebagai the watch $\operatorname{dog}$ (anjing penjaga).

Selama sekitar 25 tahun kepemimpinan Dahlan Iskan di Jawa Pos nyaris tidak ada karya jurnalistik investigatif yang dilakukan Jawa Pos. Bandingkan dengan Majalah Tempo (orantua Jawa Pos) yang mempunyai rubrik mingguan investigasi yang tampil rutin setiap minggu. Jawa Pos mengklaim diri sebagai "Tempo yang terbit setiap hari'. Tetapi, dalam hal liputan investigasi Jawa Pos tidak mengikuti jejak orangtua kandungnya.

Dalam strategi jurnalisme supermarket Jawa Pos memilih bahasa yang sederhana dan bahkan ada kecenderungan berselera rendah karena banyaknya idiom bahasa daerah yang diadopsi. Apakah Jawa Pos melakukan edukasi literasi dengan kebijakan jurnalisme supermarket itu? Pengamat media Dr. Hernani Sirikit mengatakan bahwa meskipun bahasa yang dipakai Jawa Pos tidak sekelas Surabaya Post maupun Kompas, tetapi Jawa Pos tetap patuh pada tatabahasa sesuai EYD (Ejaan Yang Diperbarui). Karena itu, Sirikit berpendapat bahwa Jawa Pos telah menjalankan fungsinya untuk melakukan pendidikan literasi kepada khalayak.

Menurut Sirikit, Jurnalisme Supermarket berbeda dengan aliran lain yang berlandaskan ideologi atau filosofi perjuangan, seperti Jurnalisme Makna Kompas, Jurnalisme Damai (Peace Journalism) yang dipromosikan oleh Johan Galtung, Jane Lynch, 
dan Anabella McGoldryck. Sedangkan Jurnalisme Sastrawi itu seperti halnya Jurnalisme Data dan Jurnalisme Presisi hanyalah teknik atau cara. Jurnalisme Supermarket lebih berorientasi pada pasar untuk reaching out menjangkau pembaca sebanyakbanyaknya.

Ditambahkan, bahasa Jawa Pos sangat popular, tidak berselera tinggi seperti Surabaya Post maupun Kompas. Hal itu secara ideal sangat memenuhi gaya bahasa media yang range pembacanya sangat luas dan heterogen. Dari lulusan SD, tukang becak, rektor maupun menteri sama nyamannya dalam membaca Jawa Pos. Bahasa Tempo terlalu indah untuk laporan investigasi, banyak dihiasi simbolisme dan metafora, hal yang hanya cocok untuk laporan faktual, terutama laporan investigatif yang serius.

Dalam hal pendidikan literasi, Sirikit setuju bahwa peran Jawa Pos cukup signifikan dalam mendorong minat baca dan melek media di kalangan publik yang luas. Seberapa signifikan dan apakah literasi positif atau tidak, menurut Sirikit perlu penelitian khusus yang lebih serius.

Pemimpin Redaksi Jawa Pos, Abdul Rokhim mengatakan bahwa Jawa Pos menerapkan Jurnalisme Supermarket sebagai strategi untuk menembus pasar. Ia melihat pangsa pasar Jawa Timur mempunyai selera yang berbeda dengan daerah lain seperti DKI Jakarta, misalnya. Karena itu, kata Rokhim diperlukan strategi khusus untuk menembus pasar itu. Ia sepakat bahwa yang dilakukan Jawa Pos adalah reaching out untuk mendapatkan 
pembaca sebanyak mungkin (McNair, 2000). Tetapi, Rokhim tidak sependapat bahwa dalam menerapkan strategi jurnalisme supermarket Jawa Pos melakukan dumbing down (pembodohan) terhadap khalayak.

Menurut Rokhim, gaya bahasa Jawa Pos mengutamakan pemahaman pembaca, sehingga selalu ditekankan sesuai dengan standar pasar pembaca. Dalam proses menjamin pemahaman itu Jawa Pos harus terus beradaptasi dengan dinamika kebahasaan yang terjadi di dunia literasi, sehingga ketika muncul istilah dari wacana publik maupun temuan dari tim editor bahasa Jawa Posmaka akan disosialisasikan secara bertahap ke pembaca sampai betul-betul diadopsi (wawancara, 2019).

Menjawab kritik bahwa dengan menerapkan Jurnalisme Supermarket Jawa Pos telah menurunkan standar bahasa Indonesia menempatkan standar bahasa Jawa Pos di bawah Kompas maupun Tempo, Rokhim mengatakan bahwa ia memahami bahwa Kompas sangat patuh pada pakem-pakem dalam penggunaan bahasa, sedangkan Tempo menekankan pada bahasa yang luwes dan sastrawi, Rokhim menambahkan Jawa Pos tidak berpretensi memosisikan diri sebagai media pengawal bahasa, namun betul-betul menjaga agar penggunaan bahasa di Jawa Pos tidak menyalahi aturan. Karena itu, Jawa Pos mempekerjakan tujuh orang editor bahasa yang bekerja full time. 
Salah satu unsur Jurnalisme Supermarket Jawa Pos adalah penyajian foto-foto yang seronok dan visuaslisasi grafis yang kuat. Mengenai hal ini Rokhim menuturkan:

' 'Kami harus terus bisa menangkap selera dan tren pembaca yang saat ini mempunyai kecenderungan menyukai sajian dengan visualisasi kuat dalam bentuk foto dan infografis."

Mengenai konsep Jurnalisme Supermarket dalam arti tersedianya semua kebutuhan pembaca, Rokhim mengatakan bahwa konsep itu tetap dipertahankan dalam kebijakan redaksional dengan terus melakukan evaluasi terhadap rubrikasi Jawa Pos, melakukan asesmen terhadap personel redaksi dan pendukung redaksi, serta selalu kritis terhadap topik-topik yang menjadi berita utama (headline). Demikian pula Jawa Pos selalu mengevaluasi rubrikasi-rubrikasi khusus agar selalu sesuai dengan topik-topik yang diminati pembaca.

Direktur Utama Jawa Pos, Leak Kustiya mengatakan, dalam hal gaya bahasa, Jawa Pos berusaha untuk mengikuti masyarakat yang terus-menerus mengalami inovasi dalam berbahasa. Komitmen Jawa Pos adalah menampilkan dan memperlakukan semua teks baik dalam judul, subjudul, pengantar, hingga semua naskah, sesuai dengan kaidah penulisan yang semestinya. Dengan begitu gaya bahasa Jawa Pos kalau tanpa sadar terus mengalami perubahan yang tidak berubah adalah ketaatannya pada cara mempresentasikannya. Pada sisi itulah aspek literasi menjadi tanggung jawab terberat, karena Jawa Pos adalah media massa tulis (Wawancara, 2019). 
Dalam hal gaya bahasa dibandingkan dengan Tempo, Kompas, atau media lain, Kustiya mengatakan bahwa Jawa Pos maunya lebih bebas. Tapi, jka seandainya Kompas maupun Tempo juga punya keinginan untuk seleluasa Jawa Pos, tentu yang membedakan adalah kemampuan dalam bergaya bahasa sambil tetap menerapkan kedisiplinan. Jawa Pos yang dianggap lebih bebas dalam berbahasa, Menurut Kustiya, konteksnya juga tidak lepas dari ikatan dengan masyarakat pembacanya, yang lebih kuat rasa Surabaya dan Jawa Timurnya. Dan itu bisa sangat berbeda dari Kompas maupun Tempo.

Di tengah kompleksitas masyarakat yang menjadi pasar Jawa Pos dan pembaca yang selalu membawa tren baru, Jawa Pos, menurut Kustiya, berusaha melihatnya dari atas. Kesederhanaan (kelugasan) visual adalah cara yang dipilih Jawa Pos. Cara pandang dari atas itu juga menjadi upaya untuk menebak arah dan tren pembaca kedepan. Bahwa kecenderungan adalah yang sederhana itu adalah yang 'chic', ide-idenya bagus, tidak rumit, dan gampang diserap secara visual (wawancara, 2019).

Menerapkan Jurnalisme Supermarket, dalam artian segala sesuatu ada tersedia, menurut Kustiya, adalah sebuah keniscayaan ketika sedari awal Jawa Pos memutuskan untuk menjadi harian umum. Apalagi Jawa Pos juga bertekad harus besar secara brand dan perusahaan. Tekad dan niat awal itulah yang membuat Jawa Pos harus menjadi supermarket, mau tidak mau harus menampung dan menjual barang apa saja. Jawa Pos sebagai 
supermarket akhirnya menjadi bebas diasumsikan dan diasosiasikan dengan apa saja termasuk dianggap tidak berkelas premium. Kalau mau steril dari asumsi ketidakpremiuman, kata Kustiya, maka jangan menjadi supermarket, dan jadilah boutique kecantikan saja.

Dengan begitu, persepsi dan citra bisa ditata lebih spesifik. Menjadi seperti Tunjungan Plasa atau Senayan City tak akan terelakkan dari percampuran barang-barang branded seperti LV, Dior, Chanel, es cendol, Chincau Station. Menyatukan barang fabrikan dengan brand internasional dengan perasan daun cincau yang ditanam di Jember dan diolah secara tradisional tentu berisiko terhadap risiko negatif. Namun sebenarnya semua sangat bergantung dari bagaimana cara mengemas dan mendisplai. Jawa Pos banyak belajar dari sukses Tunjungan Plasa, Senayan City, Grand Indonesia, dan mengambil hikmah dari banyak media yang mengalami kesulitan karena kebingungan dengan persoalan persepsi publik (wawancara, 2019).

\section{KESIMPULAN DAN SARAN}

Jurnalisme Supermarket sebagai strategi kebijakan redaksional dijalankan secara konsisten oleh Jawa Pos untuk menjangkau pembaca yang luas dari semua kalangan. Jurnalisme Supermarket menjadi ciri khas Jawa Pos yang membuatnya mampu melakukan penetrasi di pasar Jawa Timur dan Indonesia, sehingga menjadi koran dengan oplah terbesar di Tanah Air. 
Jurnalisme Supermarket membawa risiko terhadap Jawa Pos dari persepsi sebagian publik yang menganggap Jawa Pos sebagai koran bukan premium dibanding dengan pesaingnya seperti Kompas. Jawa Pos menyadari hal itu, tetapi akan tetap menerapkan kebijakan itu karena hal itu diyakini sebagai hal yang tepat untuk mempertahankan dan meningkatkan brand Jawa Pos sebagai koran terkemuka di Indonesia. 


\section{DAFTAR PUSTAKA}

Abramson, Jill. 2019. Merchants of Trurh; The Business of News and the Fight for Facts. Simon and Schuster, London.

Bagdikian, Ben. 1990. The Media Monopoly. Bacon Press, London

Castells, M. 2010. The Rise of the Network Society', Willy and Blackwell, London.

Chomsky, N, Herman. 2001. Manufacturing Consent; The Political Economy of the Mass Media. Pantheon Books, New York

Eriyanto. 2001. Analisis Wacana: Pengantar Analisis Teks Media', LKIS, Yogyakarta.

Gans, H. 2003. Democracy and the News. Oxford Press, New York.

Ishadi, SK. 2014. Media dan Kuasa. Gramedia Pustaka, Jakarta.

McQuail, D. 2011. Teori Komunikasi Massa. Salemba Humanika, Jakarta.

McNair, B. 2000. Journalism and Democracy; Evaluation of Public Sphere. Routledge, London.

McChesney, R. 2000. Rich Media Poor Democracy. London. The New Press.

Moleong, LJ. 2003. Metodologi Penelitian Kualitatif. Bandung, Rosdakarya.

Mosco, V. 2009. Politic Economy of Media, London. Sage Publication.

Mulyana, D. 2013. Metodologi Penelitian Kualitatif. Rosda, Bandung.

Murdock, G, dan Golding, J. 2001. The Political Economy of Media. Bloomsbury, London.

Nasrullah, R. 2015. Media Sosial; Perspektif Komunikasi, Budaya, dan Sosioteknologi. Simbiosa Media, Bandung.

Oetama, J, 'Pers Indonesia: Berkomunikasi pada Masyarakat Tidak Tulus', Gramedia, Jakarta, 2004

Sudibyo, A. 2019. Jagat Digital; Pembebasan dan Penguasaan. Gramedia, Jakarta.

Sugihartati, R. 2014. Perkembangan Masyarakat Informasi dan Teori Sosial Kontemporer. Kencana, Jakarta. 